\title{
ANÁLISE DE MERCADO COMO FERRAMENTA PARA A ABERTURA DE NOVOS LOTEAMENTOS
}

MARKET ANALYSIS AS TOLL FOR NEW DEVELOPMENTS STARTUP

\author{
Renata Alves Perez ${ }^{1}$ \\ Débora Sayuri Kimura ${ }^{2}$
}

\section{RESUMO}

$\mathrm{Na}$ última década ocorreu uma expansão territorial das cidades de pequeno, médio e grande porte no Brasil. Dentre os novos empreendimentos imobiliários destacam-se principalmente os residenciais. Para a abertura de novos loteamentos deve ser realizada uma pesquisa de mercado analisando o ciclo de vida familiar, renda, quais as necessidades que a família possui, idade dos integrantes, se os compradores possuem ou não filhos, enfim várias características pertinentes aos futuros compradores. O objetivo deste artigo é mostrar como inicialmente deve ser realizada uma análise de mercado para ver se há ou não viabilidade para a abertura de novos loteamentos em determinada cidade. Para esta análise escolheu-se a Região Metropolitana de Maringá - RMM.

Palavras-chave: Análise. Loteamentos. Maringá.

\section{ABSTRACT}

In the last decade there was a territorial expansion of small, medium and large sized cities in Brazil. Among the new real estate developments stand out mainly the residentials. For new developments startup, it should be made a market research analyzing the family life cycle, income, the needs that the family has, age, if have children or not, finally several characteristics of prospective buyers. This article aims to show how a market analysis must first be carried out to see whether or not there is viability for new developments startup in a particular city. For this analysis was chosen the Metropolitan Region of Maringa - RMM.

Keywords: Analysis. Developments. Maringá

\section{Introdução}

Na última década ocorreu uma expansão territorial das cidades de pequeno, médio e grande porte no Brasil. Essa expansão ocorreu principalmente devido ao crescimento econômico que o Brasil obteve com as melhorias que ocorreram na economia nessa década. Nesse panorama destacam-se principalmente os loteamentos residenciais.

Com o crescimento dos loteamentos residenciais passeou a ser necessário o desenvolvimento de novas ferramentas e metodologias com o intuito de realizar análises para viabilidade ou não da abertura de um novo loteamento. Nessas análises devem ser

\footnotetext{
1 Instituição: PUCPR - Rua Imaculada Conceição, 1155, Bairro Prado Velho - CEP: 80215-901. E-mail: renathaperez@hotmail.com

${ }^{2}$ Instituição: PUCPR - Rua Imaculada Conceição, 1155, Bairro Prado Velho - CEP: 80215-901. E-mail:dskimura@gmail.com
} 
avaliados itens como: faixa etária dos compradores; renda média mensal familiar; necessidades dos compradores (proximidades de escolas, creches, hospital, shopping center, academias, áreas verdes etc.), ciclo de vida familiar etc. Esse estudo de mercado para a implantação de novos loteamentos tem sido, de uma forma geral, bem recebido pelos donos das empresas de loteadoras.

Com o uso de estudo de mercado pode-se planejar se a implantação de tal empreendimento será viável para os investidores e, se sim, pode-se maximizar os lucros previstos. Além de visar o lucro pode-se ter uma visão global de quais itens serão projetados para o futuro loteamento.

Este artigo visa ilustrar um modelo de escolha de cidades para a abertura de novos loteamentos. Para tal estudo foi escolhida a Região Metropolitana de Maringá (RMM).

De acordo com os dados fornecidos pelo Instituto Brasileiro de Geografia e Estatística (IBGE) obtidos com o Censo 2010, as cidades que possuem porte médio, como Maringá, foram as que mais cresceram no país (em torno de 3\%). Além do crescimento as cidades de porte médio foram as que apresentaram melhor resultado do Produto Interno Bruto (PIB).

No mesmo ritmo do crescimento também ocorreu uma supervalorização dos terrenos na cidade de Maringá. Com essa supervalorização muitas pessoas têm optado por adquirir terrenos em cidades pertencentes à RMM. As cidades que mais sofreram esse impacto foram Paiçandu, Marialva e Sarandi devido à proximidade com a cidade de Maringá.

\section{Metodologia}

O desenvolvimento do modelo apresentado será composto das seguintes etapas: levantamento bibliográfico referente ao assunto; coleta de dados referentes ao local de estudo; armazenamento e análise das informações coletadas junto aos órgãos públicos (IBGE e Instituto Paranaense de Desenvolvimento Econômico e Social - IPARDES). 


\subsection{Relevância}

Este artigo almeja auxiliar profissionais do setor de loteamento a respeito do tema a ser escrito. No Brasil está ocorrendo um crescimento considerável de seus centros urbanos, com isso aumentou-se a demanda pela abertura de novos loteamentos. Como consequência surgiu a necessidade do desenvolvimento de novas ferramentas para analisar o perfil dos compradores e o local mais propício para a abertura de um novo loteamento.

\subsection{Estrutura do estudo}

O trabalho será organizado em três fases: a primeira fase será composta do levantamento bibliográfico sobre loteamento (leis de uso e ocupação do solo, aspectos legais, termos técnicos utilizados); apresentação dos dados levantados e a apresentação de um modelo para análise dos dados adquiridos.

\section{Fundamentação teórica}

\subsection{RMM}

A RMM incialmente foi instituída pela Lei Complementar $n^{\circ} 83$ de 17 de julho de 1998, Nessa fase inicial faziam parte da RMM os municípios de Ângulo, Iguaraçu, Mandaguaçu, Mandaguari, Marialva, Maringá, Paiçandu e Sarandi. Logo em seguida foi instituída a Lei n ${ }^{0} 13.565 / 2002$, na qual o município de Floresta foi agregado à RMM. Pela Lei Complementar $n^{\circ} 110 / 2005$ mais quatro municípios foram incorporados à RMM: Astorga, Doutor Camargo, Itambé e Ivatuba. Em fevereiro de 2010 foram incorporadas as cidades de Atalaia, Bom Sucesso, Cambira, Floraí, Flórida, Jandaia do Sul, Munhos de Mello, Ourizona, Presidente Castelo Branco, Santa Fé e São Jorge do Ivaí. Então, foi criada a Lei Complementar no 145 de 24 de abril de 2012 que altera o art. $1^{\text {o }}$ da lei Complementar $n^{\circ} 83$ de 17 de julho de 1998, que inclui o município de Nova Esperança à RMM. Com a incorporação desse município, a RMM apresenta um total de 26 municípios.

A Figura 1 mostra a localização da RMM no estado do Paraná. Na Figura 2 temos a RMM com seus respectivos municípios participantes. 
Figura 1 - Localização da Região Metropolitana de Maringá

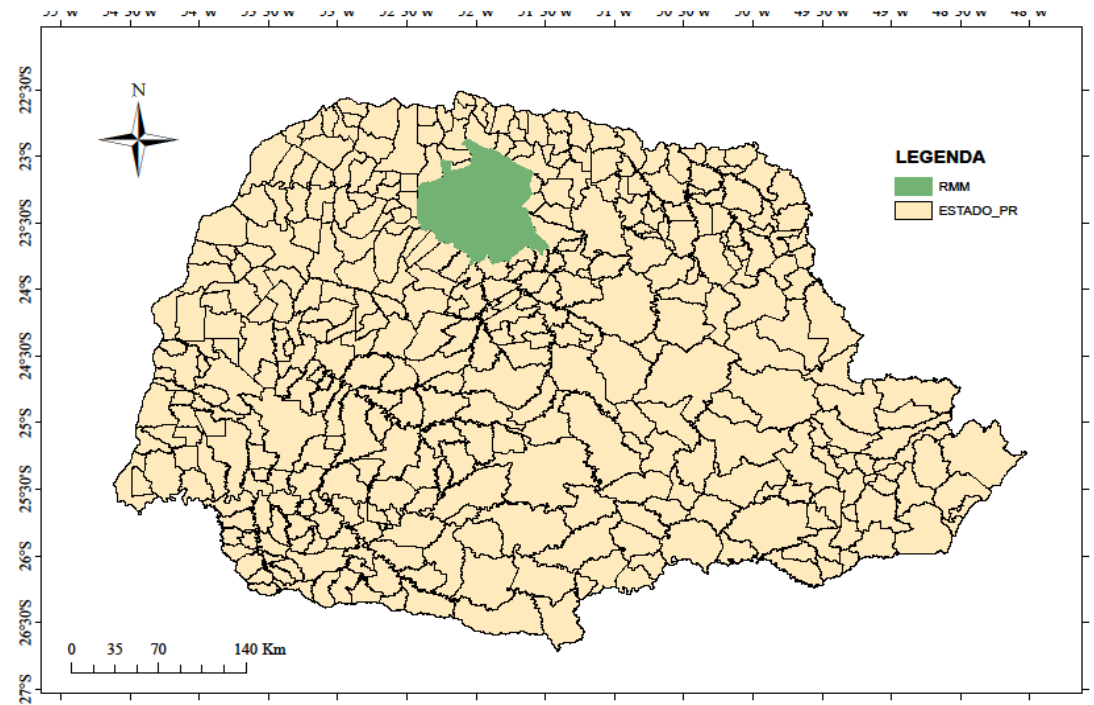

Fonte: elaborada pela autora (2014).

Figura 2 - Localização da Região Metropolitana de Maringá

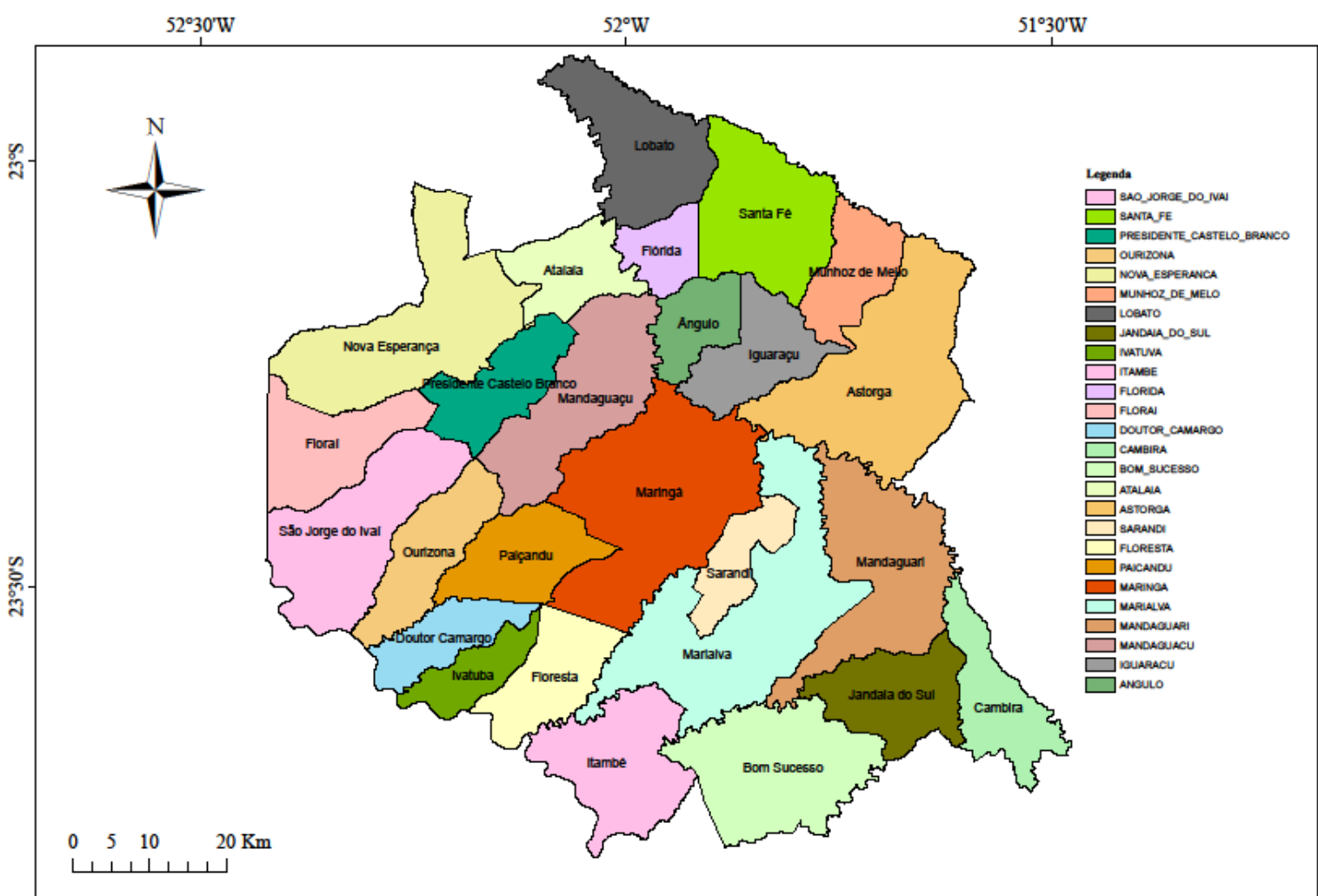

Fonte: elaborada pela autora (2014).

\subsection{Loteamento}

Segundo a Lei $\mathrm{n}^{\mathrm{o}} 6.766$, art. $2^{\circ}, \S 1^{\circ}$, o loteamento pode ser entendido como a "subdivisão de gleba em lotes destinados a edificação, com abertura de novas vias de 
circulação, de logradouros públicos ou prolongamento, modificação ou ampliação de vias já existentes" (BRASIL, 1979).

Cada cidade possui a própria lei de uso e ocupação do solo para a aprovação de loteamentos. No caso da cidade de Maringá a lei que rege é a Lei Complementar $n^{0} 888$, que regula o uso e a ocupação do solo na cidade de Maringá, respeitando as leis federais e municipais que tratam do assunto. Essa lei separa a cidade em zonas, nas quais é delimitado o que pode ser construído (residência, prédios, shopping center, hospital etc.) e a finalidade de cada lote (residencial, industrial, comercial) (MARINGÁ, 2011).

\subsection{Fatores determinantes para a aquisição de um lote}

Quando um lote é adquirido por um comprador, ele pode ser utilizado para dois fins: investimento ou moradia. No entanto, em ambos os casos o que determina sua compra são as benfeitorias feitas em torno do empreendimento (escola, creche, supermercados, farmácias, hospital, transporte público, área verde), a vizinhança, o ciclo de vida familiar, a idade e a renda mensal familiar.

Quando são utilizados critérios demográficos, pode-se fazer uma análise macroeconômica já que se tem um espaço amostral considerável. Itens de consumo, como habitação, deslocam um grande número de pessoas, assim as variáveis demográficas podem auxiliar nos empreendimentos imobiliários e no planejamento urbano (GIGLIO, 2011).

\subsubsection{Benfeitorias feitas em torno do empreendimento}

Antes de iniciar um loteamento, deve-se mapear as características da vizinhança do imóvel, como: proximidades com escolas, creches, igrejas, hospitais, supermercados, principais vias de acesso; facilidade ou dificuldade no deslocamento até o local (trânsito), quais bairros são vizinhos, padrão da vizinhança, áreas verdes, transporte público, enfim tudo o que for de interesse dos possíveis compradores.

Depois de coletados esses dados serão organizados formando um banco de dados e posteriormente lançados em um Sistema de Informação Geográfica (SIG). 


\subsubsection{Ciclo de vida familiar}

Dentre as variáveis citadas, o ciclo de vida familiar (CVF) é uma das variáveis consideráveis para a demanda.

Em um estudo realizado na cidade de Florianópolis por Fernandez (1999), constatou-se que casais sem filhos (ninho vazio) almejam um local sossegado, boa vizinhança, área verde nas proximidades, proximidade com escolas, shoppings centers, hospitais, conveniências e local de trabalho. Já para casais com filhos crianças são relevantes a proximidade com escolas, vizinhança tranquila, área verde nas proximidades assim como locais públicos para recreação, proximidade com supermercados e local de trabalho, além de policiamento intenso. E casais com filhos adolescentes visam proximidade com local de trabalho, áreas verdes e supermercados, escola dos filhos, além de um bom policiamento.

\subsubsection{Idade}

A idade é a variável com menor relevância no CVF, e possui relação direta com a questão financeira da família. Quanto mais velha é a pessoa, maior a estabilidade profissional e financeira, o que acarreta maior poder aquisitivo para a compra de um imóvel. Além de poder comprar imóveis com um maior valor, pessoas mais velhas também exigem mais benfeitorias em torno do imóvel. Outro dado a ser observado é que pessoas com uma idade mais elevada tendem a fazer poucas ou nenhuma mudança de seus imóveis.

Por outro lado, pessoas mais jovens procuram imóveis com preço mais acessível e não exigem tantos itens como a população mais idosa. As pessoas mais jovens tendem a realizar mudanças em comparação com pessoas mais velhas.

\subsubsection{Renda mensal familiar}

A renda é a variável de maior importância para esta análise. Quanto maior a renda de um indivíduo, maior será a sua mobilidade em relação ao mercado imobiliário. Na hora de escolher um imóvel, seu valor é decisivo. 
A renda está fortemente ligada à condição de pagamento do imóvel, o qual, em sua maioria, ocorre por meio de financiamento. A renda da família não age fortemente em relação à mudança de seus integrantes, mas a situação financeira da família é item determinante para a mudança dos indivíduos que compõem o meio familiar.

\subsection{4 Índice de Desenvolvimento Humano (IDH)}

O IDH mostra o desenvolvimento da educação e da saúde por município. O IDH possui quatro intervalos que servem como parâmetro para análise dos dados: muito alto $(0,80$ a 1,00$)$; alto $(0,70$ a 0,799$)$; médio $(0,60$ a 0,699$)$; baixo $(0,50$ a 0,599$)$ e muito baixo (0 a 0,499).

\subsubsection{PIB}

O PIB representa em valores monetários a soma de todos os bens e serviços produzidos em determinado local durante um período de tempo. O objetivo principal do PIB é mostrar como foi o desempenho econômico de uma região. Locais que possuem um valor elevado de PIB tendem a ter elevados índices de IDH

\subsection{Dados dos municípios pertencentes à RMM (dados censitários)}

Conforme a Figura 3 os municípios que possuem maior densidade populacional são: Maringá, Sarandi (237 a 902 hab./ $\mathrm{km}^{2}$ ) e Paiçandu (122 a 137 hab./km²). Os municípios de Nova Esperança, Mandaguaçu, Marialva, Mandaguari e Jandaia do Sul possuem densidade populacional razoável se comparados com as demais cidades (64 a $122 \mathrm{hab} . / \mathrm{km}^{2}$ ). Os demais municípios possuem densidade populacional considerada baixa comparando-se com os demais valores (IBGE, 2010).

Para o ano de 2014 o IBGE previu o crescimento populacional das cidades brasileiras. A Figura 4 mostra a previsão de crescimento populacional das cidades que compões a RMM. Na RMM as cidades que terão maior crescimento populacional serão: Maringá, Santa Fé, Mandaguaçu, Paiçandu, Sarandi e Floresta. As cidades citadas anteriormente terão crescimento populacional entre $6,30 \%$ e $8,80 \%$. As demais cidades terão um crescimento populacional de 1,70\% a 6,30\% (IBGE, 2014). 
Figura 3 - Densidade populacional (hab. $\left./ \mathrm{km}^{2}\right)$

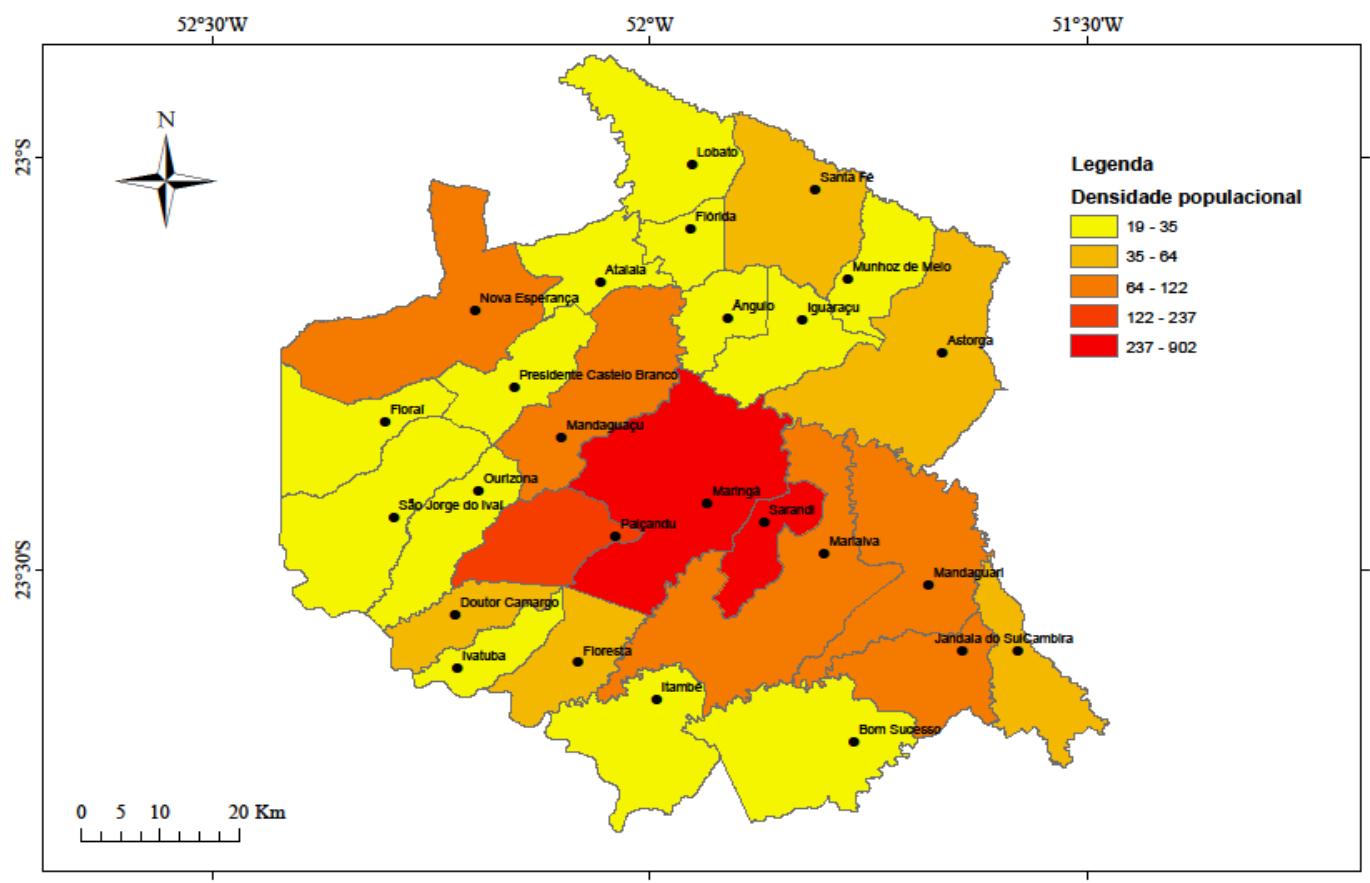

Fonte: IBGE (2010).

Figura 4 - Crescimento populacional para 2014

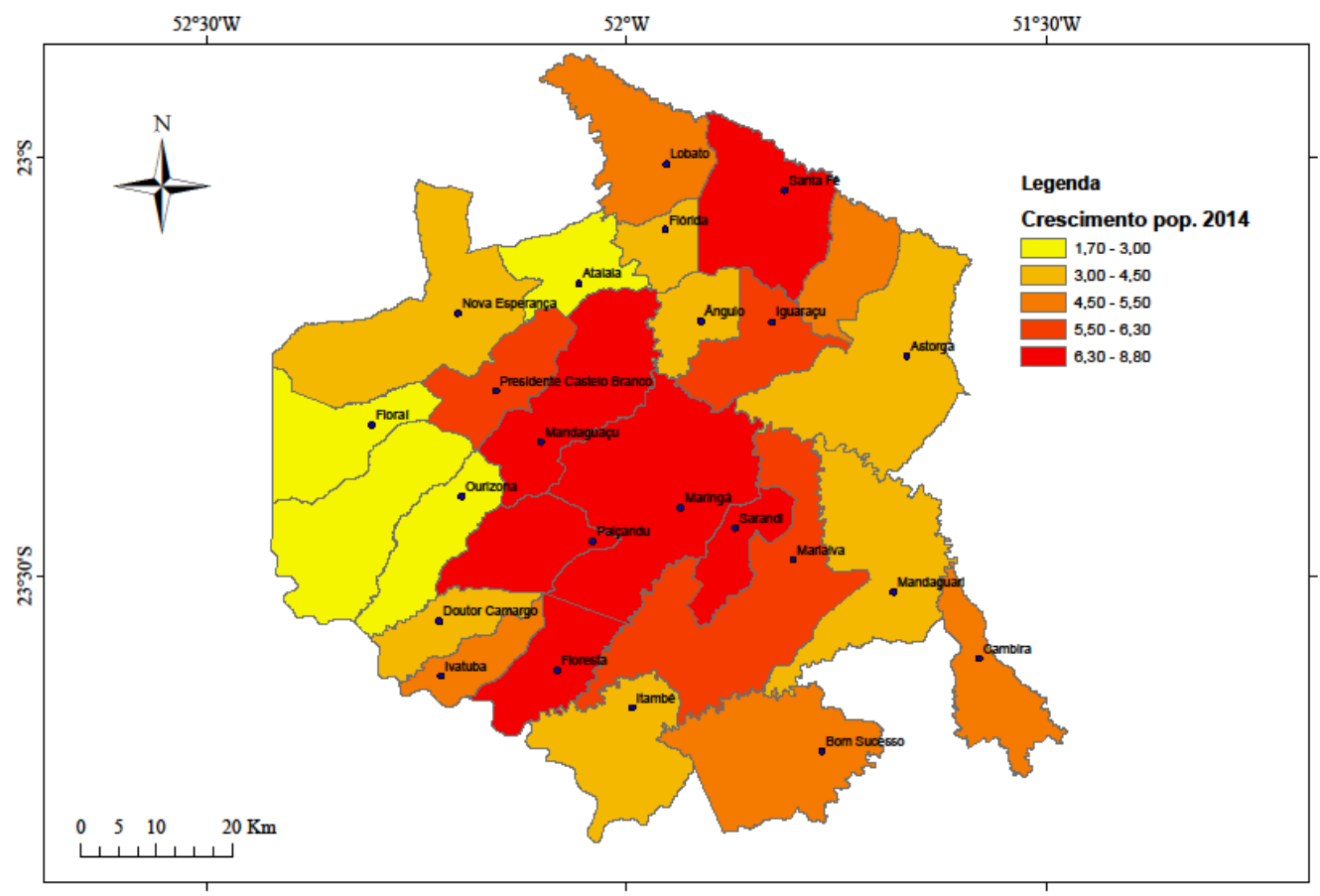

Fonte: IBGE (2010).

Conforme dados fornecidos o salário da população regional varia de 1,70 a 2,60 salários mínimos. Pelos dados apresentados, os habitantes de Maringá e Lobato possuem os maiores salários, de 2,20 a 2,60 salários mínimos. Já na faixa de salários de 
2,00 a 2,20, entram os municípios de Sarandi, Marialva, Mandaguari, Itambé e Ivatuba. Nos demais municípios a população possui renda mensal inferior a 2 salários mínimos (IBGE, 2011).

Os maiores salários concentram-se em Maringá, o que está diretamente ligado à presença de muitos autônomos, dirigentes e pessoas com terceiro grau completo. Nas demais cidades da RMM existe uma maior proporção de pessoas que trabalham nos setores primário e terciário, tarefas para as quais se exige pouca escolaridade e, como consequência, leva a baixa remuneração.

O tempo que uma pessoa estuda reflete diretamente no salário. Quanto maior o tempo de dedicação aos estudos, maior será a renda. Isso pode ser observado pelos dados obtidos pelo IDH, ou seja, em locais com valor de IDH elevado para educação, a renda também será elevada. Na cidade de Maringá, um pouco mais da metade da população com idade superior a 18 anos possui o Ensino Médio completo. Nas demais cidades esse valor não ultrapassa 30\%. Os piores resultados estão em Paiçandu (27\%) e Sarandi (22\%). Já os habitantes com terceiro grau completo e mais de 25 anos em Maringá são um pouco superior a 20\%, em Sarandi, 2,6\%, e Paiçandu, 4\%.

Em relação ao PIB a cidade de Maringá é a que possui maior valor. Em outra faixa, destacam-se os municípios de Mandaguari, Marialva e Sarandi. Esses dados podem ser explicados, pois nessas cidades encontram-se a maior concentração de empresas e indústrias na região além da proximidade com a cidade polo (IBGE, 2011).

Conforme a pirâmide etária da RMM, observa-se que possui forma de barril ou colmeia, o que mostra uma população desenvolvida com baixos índices de mortalidade infantil.

Pela pirâmide, também pode-se observar que a maior parte da população é formada por pessoas entre 19 e 59 anos. Uma população relativamente jovem e que está inserida no mercado de trabalho.

Maringá possui a $23^{\mathrm{a}}$ posição do ranking de IDH no Brasil e o melhor índice. Em contrapartida, 11 municípios da RMM possuem IDH menor do que a média nacional, que é de 0,73. Esses valores de IDH demonstram que Maringá ficou com as 
classes de alta e média e a classe baixa ficou concentrada nas demais cidades da RMM. As cidades no entorno de Maringá possuem alguns índices de IDH baixo, pois a maior parte de sua população vive na zona rural. Na maioria dos casos, quanto maior o PIB, maior é o IDH de um local.

\subsection{Supervalorização dos imóveis em Maringá}

O preço dos terrenos em Maringá subiu em média 9\% em 2013, maior que o Índice de Preços ao Consumidor (IPCA). A inflação média no Brasil no ano de 2012 fechou em $5,91 \%$.

O preço médio dos terrenos em Maringá ficou em torno de $\mathrm{R} \$ 519,59$ por metro quadrado, o que significa uma valorização de 9,2\% aa. Em anos anteriores essa valorização chegou a $20 \%$ aa.

Para ter um comparativo de preços, um terreno na cidade em Maringá, residencial e com área de $300 \mathrm{~m}^{2}$ custa $\mathrm{R} \$ 170.000,00$, e um terreno com características semelhantes na cidade de Sarandi custa $\mathrm{R} \$ 71.400,00$.

Pelo alto valor dos terrenos, muitos optam por comprar terrenos em sociedade (50\% para cada parte). Assim, é possível construir casas geminadas e instituir condomínio. Dessa maneira, cada casa terá uma escritura individual.

Mesmo com a opção de comprar terrenos em sociedade, muitos optam por comprar terrenos em cidades nas proximidades de Maringá devido ao alto valor dos imóveis. Verificou-se que muitos loteamentos foram abertos nas cidades de Sarandi, Paiçandu e Marialva devido à proximidade com a cidade de Maringá.

\subsection{Perfil dos compradores}

Em pesquisa realizada em loteadoras, observou-se que nos novos loteamentos os compradores em sua maioria têm entre 21 e 35 anos (65\%), são do sexo masculino, compram o terreno em sociedade e têm renda média de $\mathrm{R} \$ 2.500,00$ (40\%).

Dentre os compradores, $50 \%$ já possuem pelo menos dois filhos. Outro dado a acrescentar é que a maioria dos compradores (85\%) mora na RMM. Além disso, a maior 
parte das aquisições não é para especulação e sim para moradia (80\%).

\section{Considerações finais}

Para a abertura de novos loteamentos é preciso primeiramente realizar uma pesquisa de mercado para ver se existe viabilidade ou não do empreendimento.

Neste trabalho, procurou-se demonstrar quais ferramentas e informações podem ser utilizadas para a escolha do local mais apropriado para a abertura de novos loteamentos. Com o uso dessas ferramentas é possível escolher qual a melhor cidade para a abertura de um loteamento e também para qual mercado consumidor deve ser direcionado.

Em posse do local e das informações do mercado consumidor é possível saber quais benfeitorias são necessárias para atender ao público. Logo, o empreendimento será mais atrativo para a venda.

Pela análise dos fatores determinantes da compra de um imóvel, observou-se que o fator renda é o de maior relevância. No caso da RMM, notou-se que a cidade de Maringá concentra os melhores índices, como salário, PIB educação e crescimento. Com o levantamento realizado, as cidades da RMM também são locais para abertura de novos empreendimentos imobiliários, pois, além de possuírem renda, seus indicadores socioeconômicos são bons.

\section{REFERÊNCIAS}

AMORIM, M. G. O; RUMEL, C. R. A indústria de loteamentos e o planejamento estratégico: uma proposta de análise para seleção de municípios alvo e prospecção de áreas para o mercado imobiliário de médio e alto padrão. $13^{\mathrm{a}}$ Conferência Internacional da LARES, 2013.

FERNANDEZ, J. A. C. G. E. Preferência quanto a localização e influência no ciclo de vida familiar. 1999. 153 f. Dissertação (Doutorado) - Universidade Federal de Santa Catarina, 1999. 
GIGLIO, E. M. O comportamento do consumidor. 4.ed. São Paulo: Editora Pioneira Thomson, 2011.

RESCHILIAN, R. P; UEHARA, A. Y. Desafios à questão metropolitana: o processo de organização do espaço urbano e regional de Maringá. Oculum Ensaios, n. 15, p. 76-87, 2012.

RODRIGUES, A. L. A Ocupação urbana da Região Metropolitana de Maringá: uma história de segregação. Revista Paranaense de Desenvolvimento, n. 108, p. 61-86, 2005 .

RODRIGUES, A. L. O IDH e a desigualdade na Região Metropolitana de Maringá. Jornal da UEM, n. 116, p. 1-2, 2013.

MAGALHÃES, M. V; CINTRA, A. P. U. Dinâmica demográfica do Paraná: tendências recentes, perspectivas e desafios. Revista Paranaense de Desenvolvimento, n. 122, p. 263-291, 2012.

VERCEZI, J. T; TÖWS, R. L; MENDES, C. M. O mercado imobiliário da Região Metropolitana de Maringá e seus Reflexos na ocupação socioespacial dos condomínios residenciais horizontais. Boletim de Geografia, v. 26/27, n. 1, p. 71-79, 2009.

BRASIL. Lei $\mathrm{n}^{0}$ 6.766, de 19 de abril de 1979. Diário Oficial. Brasília, 2012. Disponível em: <www.planalto.gov.br>. Acesso em: 6 set. 2014.

GOVERNO DO ESTADO DO PARANÁ. Lei Complementar ${ }^{\circ}$ 83, de 17 de julho de 1998. Diário Oficial. Curitiba, 1998. Disponível: <www.legisgacao.pr.gov.br>. Acesso em: 6 set. 2014.

GOVERNO DO ESTADO DO PARANÁ. Lei $\mathrm{n}^{\circ}$ 13.565, de 27 de maio de 2002. Diário Oficial. Curitiba, 2002. Disponível em: <www.legisgacao.pr.gov.br>. Acesso em: 6 set. 2014.

GOVERNO DO ESTADO DO PARANÁ. Lei Complementar $n^{\circ} 110$, de 25 de agosto de 2005. Diário Oficial. Curitiba, 2005. Disponível em: <www.legisgacao.pr.gov.br>. Acesso em: 06 set. 2014. 
GOVERNO DO ESTADO DO PARANÁ. Lei Complementar $n^{\circ}$ 145, de 24 de abril de 2012. Diário Oficial. Curitiba, 2012. Disponível em: 〈www.legisgacao.pr.gov.br>. Acesso em: 06 set. 2014.

MARINGÁ. Prefeitura Municipal. Lei Complementar nº 888, de 26 de julho de 2011. Diário Oficial. Maringá, 2011. Disponível em: <www.leismunicipais.com.br〉. Acesso em: 10 set. 2014.

IBGE. Censo 2010. Disponível em: <www.ibge.gov.br>. Acesso em: 23 out. 2014.

IPARDES. Municípios e regiões. Disponível em: <www.ipardes.gov.br/cadernos〉. Acesso em: 15 ou. 2014.

Recebimento dos originais: 25/01/2014

Aceitação para publicação: 16/08/2014 